\title{
A CONFIGURAÇÃO DO CARTEL NO MERCADO DE SAÚDE SUPLEMENTAR: SITUAÇÃO DA AUTOGESTÃO
}

\section{Natanael Dantas Soares ${ }^{1}$}

\section{RESUMO}

Este trabalho aborda a legitimidade da associação de operadoras de autogestão na negociação com prestadores de serviços de saúde para definição de preços dos serviços e a configuração do cartel no mercado de saúde suplementar à luz da legislação que regulamenta as relações de mercado e de consumo, cuja interpretação teleológica e sistemática indica configuração do cartel na união de prestadores de serviços para definir, de forma coordenada, os preços dos serviços ou materiais e no acordo orquestrado de operadoras para determinar o valor das mensalidades dos planos de saúde, com foco na proteção do interesse dos consumidores.

PALAVRAS-CHAVE: CARTEL; MERCADO DE SAÚDE SUPLEMENTAR; AUTOGESTÃO EM SAÚDE; LIVRE CONCORRÊNCIA; DEFESA DO CONSUMIDOR.

\section{THE CARTEL CONFIGURATION IN SUPPLEMENTARY HEALTH MARKET: SELF-MANAGED INSURANCE SITUATION}

\begin{abstract}
This study approaches the legitimacy of self-managed health insurance suppliers association in negotiations with health services providers to determine services prices and cartel configuration in supplementary health market according to legislation that rules the market and consume relationships, such a teleological and systematic interpretation indicates cartel configuration in the collusion of health services providers to coordinately determine the services and materials prices and of health insurance suppliers to determine the users monthly payment, focusing on consumers interest.
\end{abstract}

\footnotetext{
${ }^{1}$ Advogado; mestre em Direito Ambiental, especialista em Autogestão em Saúde, Gestão de Sistemas de Saúde e Administração dos Serviços de Saúde; professor na pós-graduação das Faculdades Borges de Mendonça. natanael.soares1@gmail.com.
} 
KEYWORDS: CARTEL; HEALTH SERVICES MARKET; SELF-MANAGED HEALTH INSURANCE; FREE COMPETITION; CONSUMER DEFENSE.

\section{INTRODUÇÃO}

Este trabalho aborda a legitimidade da associação de operadoras de planos de saúde na modalidade autogestão na negociação com prestadores de serviços de saúde e fornecedores de materiais médico-hospitalares para definição de preços dos serviços e a configuração do cartel no mercado de saúde suplementar à luz da legislação que regulamenta as relações de mercado e de consumo.

Essa abordagem explora a legislação e a doutrina relacionadas aos temas tratados e destaca alguns processos administrativos do Conselho Administrativo de Defesa Econômica - CADE - referentes a situações pontuais em processos negociais entre operadoras de planos de saúde e prestadores de serviços de saúde.

O mercado de saúde suplementar, constituído por prestadores de serviços de saúde, fornecedores de medicamentos, materiais e equipamentos médico-hospitalares, operadoras de planos de saúde e seus usuários, compõe o sistema de saúde brasileiro instituído pela Constituição Federal e sua movimentação se dá com as inter-relações desses atores.

O mercado de saúde está inserido num ambiente maior, que abrange todas as relações e transações de natureza econômica, com regulamentações gerais e específicas para manutenção da chamada ordem econômica, assim entendida a situação de equilíbrio de forças entre os seus diversos atores.

Os conflitos entre operadoras e prestadores ocorrem quando os seus interesses se chocam nos processos de negociação dos preços dos serviços, em razão da natural tendência de cada um supervalorizar as suas pretensões no tratamento das questões econômicofinanceiras.

A Lei $n^{\circ}$ 13.003/2014 e sua regulamentação pela Agência Nacional de Saúde Suplementar (ANS) estabeleceram critérios e procedimentos para a definição de preços e condições no relacionamento entre operadoras e prestadores dos serviços, mantendo, no entanto, a negociação entre as partes como prioridade nessa definição. 


\section{A CONFIGURAÇÃO DO CARTEL NO MERCADO DE SAÚDE SUPLEMENTAR:}

SITUAÇÃO DA AUTOGESTÃO

As operadoras de planos de saúde têm características específicas que levaram o legislador a agrupá-las por afinidades na constituição e operacionalização, classificando-as nas modalidades cooperativas, autogestão, medicina de grupo, seguradoras e filantropia.

A modalidade autogestão está destacada neste trabalho em razão de seu tratamento especial na legislação e decisões do Conselho Administrativo de Defesa Econômica - CADE - em processos administrativos para apuração de infração à ordem econômica com condenação da União Nacional de Instituições de Autogestão em Saúde UNIDAS.

O cartel constitui uma estratégia de defesa de interesses notoriamente nociva ao equilíbrio nas relações de mercado, inclusive o de saúde suplementar, sendo recomendada neste trabalho uma análise mais apurada da situação e da legislação para uma maior segurança na sua configuração.

No mercado de saúde suplementar, há duas vertentes de preços: uma, a das mensalidades dos planos de saúde, cujo dimensionamento envolve diretamente operadoras e usuários e outra, a dos serviços contratados, que envolve diretamente operadoras e prestadores de serviços e atinge o usuário com o reflexo no aumento das mensalidades ou na coparticipação no pagamento desses serviços, dualidade que merece ser considerada na análise da configuração do cartel.

A análise da legislação e da estrutura legalmente estabelecida para a proteção do mercado mostra uma conjugação necessária entre a defesa da concorrência e a defesa do consumidor, com a integração do Sistema Brasileiro de Defesa da Concorrência (SBDC) e o Sistema Nacional de Defesa do Consumidor (SNDC), o que é determinante na avaliação da configuração do cartel.

\section{MERCADO DE SAÚDE SUPLEMENTAR}

O sistema de saúde brasileiro é composto por dois subsistemas: o público, que é o Sistema Único de Saúde (SUS) e o privado, constituído pelos subsetores da saúde suplementar, que é o predominante nesse subsistema, composto pelos serviços financiados 
pelos planos e seguros de saúde, e o liberal clássico, composto pelos serviços particulares autônomos (CONASS, 2011, p. 56).

Denomina-se mercado de saúde suplementar o ambiente e as situações em que acontecem as relações de negociação, prestação e pagamento dos serviços de saúde, assim denominado em razão das transações comerciais de compra e venda de materiais, medicamentos, equipamentos, serviços e planos de saúde, cujos atores são prestadores de serviços de saúde, fornecedores de medicamentos, materiais e equipamentos médicohospitalares e operadoras e usuários de planos de saúde (SOARES, 2010, p. 454).

O mercado de saúde suplementar restringe-se às relações econômicas que envolvem as operadoras de planos de saúde privados, com a exclusão, portanto, do relacionamento entre os prestadores de serviço de saúde e fornecedores com o poder público para a assistência à saúde da população atendida pelo Sistema único de Saúde (SUS).

Esse mercado é complexo em razão da sensibilidade do seu objeto finalístico e do choque de interesses dos seus diversos atores, num ambiente em que o individualismo impera pela desconsideração de que a aplicação dos recursos nesse mercado deve visar ao benefício da coletividade à qual pertence o indivíduo que está, em determinado momento, utilizando os serviços e, portanto, consumindo os recursos (SOARES, 2010, p. 454).

O relacionamento entre os atores desse mercado nem sempre é pacífico, haja vista que ainda perdura entre operadoras, prestadores e fornecedores um ranço de desconfiança generalizada no tratamento das questões econômico-financeiras, com conflitos que residem na presunção recíproca de peraltices desonestas na cobrança e no pagamento dos serviços prestados e, como átomo de todo esse relacionamento, o usuário que demanda procedimentos e materiais nem sempre cobertos pelo seu plano de saúde.

Mostra-se mais pertinente identificar o usuário como átomo desse processo do que como centro, haja vista que toda a engrenagem assistencial é acionada a partir da demanda por uma intervenção em sua saúde, mas, na prática, ele nem sempre é considerado pelos demais atores nas discussões do seu caso, quando o foco é mais fortemente direcionado para os aspectos econômico-financeiros.

O mercado de saúde suplementar foi estruturado, em linhas gerais, a partir de quatro segmentos, que são medicina de grupo, seguradoras, cooperativas e autogestão, cada um com suas características e formas de organização, inclusive com órgãos de representação 


\section{A CONFIGURAÇÃO DO CARTEL NO MERCADO DE SAÚDE SUPLEMENTAR: SITUAÇÃO DA AUTOGESTÃO}

social diferentes, mas a natureza da atividade por elas desenvolvida é basicamente a mesma e, independentemente da modalidade, todas as organizações do setor administram "pecúlios", formados pelas contribuições diretas dos indivíduos ou dos seus empregadores, ou por ambos, cujo objetivo é garantir assistência à saúde (CONASS, 2011, p. 12).

Esse mercado é regulamentado pela Lei $n^{0}$ 9.656/98 e regulado pela Agência Nacional de Saúde Suplementar (ANS), criada pela Lei $n^{\circ}$ 9.961/2000, cujos registros mostram em março/2017 uma população de 70.074.472 usuários de planos de saúde, sendo 47.606.341 de assistência médico-hospitalar e 22.468.131 de planos exclusivamente odontológicos (ANS, 2017).

Para Soares (2010, p. 454), os atores no mercado de saúde suplementar dependem uns dos outros para manterem-se e a falta de reconhecimento dessa realidade provoca a exploração dos serviços na busca de vantagens excessivas, sem a consciência de que o desaparecimento de um ator pode prejudicar todo o mercado.

Segundo Vilarinho (2004, p. 5), no Brasil, o acirramento da concorrência no mercado de saúde suplementar e a prevalência das vantagens competitivas evidenciaram a vulnerabilidade dos consumidores, e, em vários casos, dos próprios profissionais de saúde, os efetivos prestadores dos serviços.

Os prestadores de serviços de saúde que participam das discussões econômicofinanceiras no mercado de saúde são hospitais, clínicas, médicos, odontólogos, psicólogos, fisioterapeutas e fonoaudiólogos, os quais percebem, muitas vezes, somente os seus efeitos, por serem os processos negociais conduzidos geralmente por entidades que os representam.

A regulamentação dos planos de saúde e a atuação da ANS envolvem também os prestadores de serviços, por terem eles participação fundamental na assistência à saúde no setor privado, haja vista que constituem com operadoras e usuários o tripé necessário desse processo.

Os arts 17 e 18 da Lei $n^{\circ}$ 9.656/98, com as alterações promovidas pela Lei ${ }^{\circ}$ 13.003/2014, dão à ANS o impulso necessário para ampliar a sua intervenção no âmbito da rede credenciada nos processos assistenciais e negociais, com o propósito de proteger o direito do consumidor. 
A teoria econômica neoclássica assume o postulado da informação perfeita entre compradores e vendedores, mas no caso da saúde o sistema lida com informações assimétricas, especialmente, na relação entre médicos e pacientes (VIANA et al, 2002, p. 204).

\subsection{OPERADORAS DE PLANOS DE SAÚDE}

Os planos de saúde privados passaram a ter regulamentação específica em 1998, com o advento da Lei $\mathrm{n}^{\circ}$ 9656/98, que estabeleceu conceitos e normas para contratação de planos de saúde, e a Lei no 9961/2000, que criou a Agência Nacional de Saúde Suplementar (ANS).

O art. $1^{\circ}$ da Lei ${ }^{0}$ 9.656/98 define como operadora de plano de saúde a pessoa jurídica constituída sob a modalidade de sociedade civil ou comercial, cooperativa, ou entidade de autogestão, que opere produto, serviço ou contrato de plano privado de assistência à saúde, este definido como a prestação continuada de serviços ou cobertura de custos assistenciais a preço pré ou pós-estabelecido, por prazo indeterminado, com a finalidade de garantir, sem limite financeiro, a assistência à saúde, pela faculdade de acesso e atendimento por profissionais ou serviços de saúde, livremente escolhidos, integrantes ou não de rede credenciada, contratada ou referenciada, visando à assistência médica, hospitalar e odontológica, a ser paga integral ou parcialmente pela operadora contratada, mediante reembolso ou pagamento direto ao prestador, por conta e ordem do consumidor.

A Lei $n^{0}$ 9.961/2000 estabelece em seu art. $4^{\circ}$, inciso X, como competência da ANS a definição da segmentação das operadoras e administradoras de planos privados de assistência à saúde, observando as suas peculiaridades.

A Resolução RDC n 39/2000, da ANS, define, em seu art. $1^{\circ}$, como Operadoras de Planos de Assistência à Saúde as empresas e entidades que operam, no mercado de saúde suplementar, planos de assistência à saúde e, em seu art. 10, classifica-as nas modalidades de administradora, cooperativa médica, cooperativa odontológica, autogestão, medicina de grupo, odontologia de grupo e filantropia.

Originalmente, a Lei $\mathrm{n}^{\circ}$ 9.656/98 distinguiu planos e seguros de saúde, reconhecendo as seguradoras como operadoras, porém a MP nº 1.908-18, de 24/09/1999, 


\section{A CONFIGURAÇÃO DO CARTEL NO MERCADO DE SAÚDE SUPLEMENTAR:}

SITUAÇÃO DA AUTOGESTÃO

extinguiu o seguro de saúde e passou a exigir das seguradoras especialização para atuar no mercado de saúde, tema regulamentado pela Lei $n^{\circ}$ 10.185/2001 e RDC n 65/2001, da ANS.

A associação de operadoras numa negociação tem a finalidade de fortalecê-las mediante equalização das suas dimensões individuais e oferecimento aos prestadores da vantagem de concentração do processo negocial e da demanda e, em contrapartida, a possibilidade de redução nos preços dos serviços.

As cooperativas médica e odontológica são representadas mais expressivamente pela Unimed e Uniodonto, respectivamente; a autogestão, pela União Nacional das Instituições de Autogestão em Saúde - UNIDAS; a medicina de grupo, pela Associação Brasileira de Medicina de Grupo - Abramge - e as seguradoras, pela Federação Nacional das Empresas de Seguros Privados e de Capitalização - FENASEG.

\subsubsection{Operadoras na Modalidade Autogestão}

A Lei ${ }^{\circ} 9.656 / 98$, ao definir operadoras de plano de saúde em seu art. $1^{\circ}$, inciso II, citou especificamente duas das modalidades, as cooperativas e as entidades de autogestão, destaque que se deve ao interesse público, no caso das cooperativas, nos termos do art. $1^{\circ}$ da Lei $\mathrm{n}^{0}$ 5.764/71, que define a Política Nacional de Cooperativismo e no caso das entidades de autogestão, ao seu propósito, entendendo o legislador que essas modalidades tinham peculiaridades que as diferenciavam das operadoras constituídas na forma de sociedade civil ou comercial.

No processo de regulamentação dos planos de saúde, a autogestão recebeu, além desse destaque no citado dispositivo legal, sempre atenção especial, haja vista ter normatização específica pelo CONSU, na Resolução CONSU $n^{0}$ 05/98, e pela ANS, na Resolução $\mathrm{RN} \mathrm{n}^{\circ}$ 137/2006, cujo art. 2º I, a define como a pessoa jurídica de direito privado que, por intermédio de seu departamento de recursos humanos ou órgão assemelhado, opera plano privado de assistência à saúde exclusivamente aos beneficiários que o próprio dispositivo legal determina.

Na autogestão, conforme define a $\mathrm{RN} \mathrm{n}^{\circ}$ 137/2006, da ANS, a assistência à saúde é assegurada aos empregados de empresas ou servidores públicos e respectivos familiares e 
pode ser organizada e administrada diretamente pela empresa, inserida nas atribuições de seu departamento de recursos humanos, ou gerida pelos próprios empregados ou servidores, por meio de caixas de assistência, associações e sindicatos.

A contraprestação pecuniária do usuário na autogestão é denominada contribuição e é constituída por percentual da remuneração do empregado ou servidor, por quotização, coparticipação no pagamento dos serviços assistenciais utilizados ou uma combinação dessas formas.

O art. $3^{\circ}$, parágrafo único, da Resolução CONSU nº 08/98, estabelece que nos planos de contratação coletiva empresarial custeados integralmente pela empresa não é considerada contribuição a co-participação do consumidor, única e exclusivamente em procedimentos, como fator moderador, na utilização dos serviços de assistência médica e/ou hospitalar.

Qualquer autogestão está vinculada a um grupo predeterminado de associados, ou beneficiários, não sendo organizações que atuam no mercado, não comercializam planos para empresas, nem vendem planos individuais ou familiares (CONASS, 2011, p. 17).

Essa modalidade é representada pela União Nacional das Instituições de Autogestão em Saúde - UNIDAS, resultante da fusão entre o Comitê de Integração das Entidades Fechadas de Autogestão em Saúde - CIEFAS - e a Associação Brasileira das Autogestões em Saúde Patrocinadas pelas Empresas - ABRASPE.

\section{CARTEL}

A definição prevalente de cartel é o acordo explícito ou implícito entre concorrentes para fixação de preços ou distribuição da participação no mercado de forma coordenada ou orquestrada para, mediante eliminação da concorrência, aumentar os lucros dos participantes em detrimento do interesse do consumidor.

A referência ao cartel apenas como forma de aumentar preços é inadequada, pois o restringe a fornecedores e, portanto, desconsidera a possibilidade de cartéis para redução de preços, como no caso de adquirentes de matérias-primas para sua atividade econômica, na forma de monopsônios, que se caracterizam pela existência de vários fornecedores e apenas um adquirente e oligopsônios, com a existência de vários fornecedores e um número muito limitado de compradores, equivalendo, em seus efeitos concorrenciais, aos monopólios e 


\section{A CONFIGURAÇÃO DO CARTEL NO MERCADO DE SAÚDE SUPLEMENTAR:}

SITUAÇÃO DA AUTOGESTÃO

oligopólios, respectivamente, estes com a concentração do poder de venda e aqueles, o de compra.

O cartel se verifica inclusive quando o grupo define preços diferenciados de forma concertada, pois a sua caracterização se dá pela eliminação da concorrência com a falta de liberdade para que cada um estabeleça individualmente o seu preço.

Evenett, Levenstein e Suslow (2001, p. 14) destacam três características dos cartéis: os cartéis envolvem acordos secretos entre empresas, o objetivo desses acordos é assegurar ganhos pecuniários para os membros do cartel e sustentar o cartel demanda atenção cuidadosa para fazer acordos entre as empresas compatíveis com o incentivo elaborado.

Uma propriedade que é comum a todos os cartéis examinados era que os preços colusivos eram os mesmos para todos os membros do cartel e que uma segunda característica comum a diversos cartéis era que eles concordariam com um preço ideal, ou recomendado, e um preço piso, ou mínimo ou fundo, que era mais baixo do que o preço ideal (HARRINGTON, 2006, p. 6).

A formação do cartel é mais fácil do que a sua manutenção, haja vista que a junção dos atores se dá exclusivamente por conveniência econômica, completamente desprovida de ideologia, o que a torna constantemente vulnerável pela suscetibilidade do despertamento individual para novos interesses.

A instabilidade e a dificuldade de coordenação do cartel ocorrem quando há uma grande diferenciação entre os seus membros, que pode ser em relação à multiplicidade de variações da participação relativa de cada produtor, à valorização distinta do produto no mercado, às diferenças de custos e objetivos (SAES, 1997, p. 180).

A formação do cartel é de difícil execução porque demanda uma unanimidade, na qual cada membro sofrerá a tentação constante de baixar o preço ou melhorar as condições para vender mais, funcionando como um castelo de cartas que, dependendo da carta bulida, pode desmoronar tudo de uma só vez (RYPL, 2006, p. 35).

Um cartel bem-sucedido demanda não apenas um acordo entre as empresas envolvidas, mas também algum método pelo qual elas possam vigiar-se mutuamente e 
também alguma maneira para evitar a competição de outras empresas que estejam fora do cartel. (SOWELL, 2011, p. 160).

A maior dificuldade para formar um cartel é manter a solidariedade entre os seus membros, pois o cartel criará um nível de perda de peso morto no mercado, definido como um potencial excesso de consumidores e produtores que poderia ser aproveitado no mercado, mas por alguma razão não são (DEPKEN, 2006, p. 188).

O cartel é legitimado pelo processo negocial, na medida em que os tomadores do serviço ou os compradores do produto acordam, voluntariamente, os preços com o grupo de fornecedores com a desconsideração da orquestração entre eles, restringindo-se essa legitimação, no entanto, a esse negócio, haja vista que a ilegalidade da formação do cartel continua e poderá ser questionada em outras oportunidades, inclusive em novas negociações com esses atores que, por alguma conveniência a legitimaram.

No Brasil, Decreto Presidencial de 07/08/2008 instituiu o Dia Nacional do Combate a Cartéis, a ser comemorado anualmente no dia 8 de outubro, data de publicação do decreto no Diário Oficial da União.

A Lei $n^{0}$ 12.529/2011 define, em seu art. 36, que constituem infração da ordem econômica, os atos que tenham por objeto ou possam limitar, falsear ou de qualquer forma prejudicar a livre concorrência ou a livre iniciativa, dominar mercado relevante de bens ou serviços, aumentar arbitrariamente os lucros e exercer de forma abusiva posição dominante.

A posição dominante é presumida no $\S 2^{\circ}$ do referido artigo sempre que uma empresa ou grupo de empresas for capaz de alterar unilateral ou coordenadamente as condições de mercado ou quando controlar 20\% (vinte por cento) ou mais do mercado relevante, podendo este percentual ser alterado pelo CADE para setores específicos da economia.

Convém destacar, com base no inciso IV do dispositivo legal citado, que o exercício de posição dominante somente constitui infração quando abusivo, isto é, quando tem o deliberado propósito de obter vantagens que exorbitem os referenciais disponíveis, o bom senso e a boa-fé, com notória prevalência de um desequilíbrio de forças e indiferença quanto aos prejuízos que tal conduta cause aos demais atores.

A disposição do $\S 3^{\circ}$ do referido artigo 36 destaca a figura do ajuste entre concorrentes na fixação de preços para caracterização do cartel, o que exclui a possibilidade 


\section{A CONFIGURAÇÃO DO CARTEL NO MERCADO DE SAÚDE SUPLEMENTAR:}

SITUAÇÃO DA AUTOGESTÃO

de sua formação por grupos ou associações de consumidores, considerando a Política Nacional de Relações de Consumo, instituída pela Lei nº 8.078/90.

\subsection{CARTEL NA SAÚDE SUPLEMENTAR}

Considerando que o cartel se caracteriza por atitudes dos atores do mercado que configurem no seu inter-relacionamento o propósito de obtenção de vantagens excessivas de uns em detrimento de outros e que, mesmo que em perspectiva, venham a prejudicar o interesse dos consumidores, necessário se faz o esclarecimento de que nem toda junção de atores configura essa situação ilegal e prejudicial ao equilíbrio das relações de mercado.

No mercado de saúde suplementar existe uma tríade indispensável para o seu funcionamento, formada por prestadores de serviços e fornecedores, que suprem direta e operacionalmente a necessidade de saúde da população assistida por plano de saúde, pelas operadoras de planos de saúde, que assumem o pagamento por esse fornecimento como terceiro-pagador, e pelos usuários, que utilizam, efetiva ou potencialmente, os serviços e materiais e, para isso, assumem uma contraprestação pecuniária perante a operadora.

O relacionamento entre os componentes dessa tríade é integrado no que tange a sua finalidade, qual seja, o de assegurar o atendimento ao usuário quando ele precisa de uma intervenção assistencial de saúde, mas demanda uma distinção na definição do seu equilíbrio quando se trata das relações contratual e comercial, no estabelecimento de preços.

A figura do terceiro-pagador, caracterizada pelo fato de prestadores e fornecedores se relacionarem diretamente com os usuários na prestação do serviço e no fornecimento de materiais e a respectiva conta ser paga pela operadora, dá uma conotação sui generis a essa relação comercial que permite abordar diferentemente o contrato de plano de saúde, celebrado entre a operadora e o usuário, e o de credenciamento, celebrado entre operadora e prestador de serviço ou fornecedor de material.

Essa distinção é fundamental na avaliação do processo negocial para estabelecimento de preços, haja vista que no contrato de plano de saúde a operadora assume a posição de fornecedor, nos termos do art. $3^{\circ}$ da Lei $n^{\circ} 8.078 / 90$, enquanto no contrato de 
credenciamento ela se apresenta como interveniente, na condição de responsável financeiro, numa relação de consumo que se estabelece, de fato, entre o prestador e o usuário.

Nesse aspecto, destaca-se que o plano de saúde é constituído por uma coletividade, com pessoas que se dispõem a recolher conjuntamente uma quantia mensal numa proporcionalidade pré-determinada, denominada contraprestação, com o propósito de garantir a assistência à saúde de todos e de qualquer deles na medida da necessidade de cada um, na forma de mutualismo, que se caracteriza pelo compartilhamento de necessidades e possibilidades, recíproca e tacitamente assumido.

Os preços de serviços e materiais utilizados na assistência aos usuários e pagos pelas operadoras são estabelecidos pelos prestadores e fornecedores algumas vezes sem uma base tecnicamente sustentável ou, em outras palavras, aleatoriamente e isso dificulta o processo negocial porque as operadoras também nem sempre têm parâmetros seguros para suas posições e essa ignorância generalizada provoca resultados prejudiciais aos usuários, seja com a paralisação do atendimento por falta de acordo ou com o fechamento de acordos com preços inadequados, que repercutirão na definição das contraprestações financeiras dos beneficiários dos planos.

As negociações conduzidas por sindicatos, associações, cooperativas ou qualquer outra forma de congregação de prestadores de serviços de saúde com o propósito de impor preços abusivos, assim considerados os que extrapolam o limite da coerência ou as referências estabelecidas no art. 39, incisos V e $\mathrm{X}$, da Lei $\mathrm{n}^{\circ}$ 8.078/90, são passíveis de serem caracterizadas como cartelização, como se vê em processos administrativos no CADE, tais como PA nº 08000.011517/94-35, PA nº 08012.009987/1998-13, PA nº 08012.006397/97-02, PA $n^{\circ}$ 08012.004372/2000-70, PA n $n^{\circ} 08012.004373 / 2000-32$ e, ainda em tramitação, PA n ${ }^{\circ}$ 08012.004276/2004-71.

No entanto, a discussão das questões econômicas entre operadoras de planos de saúde e seus usuários assume uma conotação diferente da que acontece entre operadoras e prestadores de serviços, considerando que nessa situação os interesses da operadora se contrapõem aos do usuário no que tange ao dimensionamento da contraprestação.

A definição da mensalidade do plano de saúde se dá mediante estudos atuariais, que consideram, dentre outros fatores, o volume de despesas gerado pelos usuários em determinado período, que, por sua vez, é determinado também pelo preço negociado pela 


\section{A CONFIGURAÇÃO DO CARTEL NO MERCADO DE SAÚDE SUPLEMENTAR:}

SITUAÇÃO DA AUTOGESTÃO

operadora com prestadores e fornecedores, o que implica dizer que as mensalidades a serem pagas pelos usuários serão determinadas pelos preços praticados pelos prestadores e fornecedores.

Alguns planos de saúde utilizam como mecanismos de regulação financeira da demanda a co-participação ou a franquia, autorizadas pelo art. $1^{\circ}, \S 2^{\circ}$, da Resolução CONSU $n^{\circ}$ 08/98, nas quais o usuário arca, além da mensalidade ou em substituição a ela, com parte do pagamento devido pela operadora ao prestador pelo seu atendimento.

A oneração do usuário com a repercussão direta ou indireta em seu orçamento dos preços pagos aos prestadores e fornecedores pela sua operadora inclui esta, enquanto gestora dos interesses de uma coletividade no processo negocial com prestadores de serviços e fornecedores de materiais, na categoria de consumidor por equiparação, nos termos do parágrafo único do art. $2^{\circ}$ da Lei $n^{\circ} 8.078 / 90$, o que afasta a possibilidade de caracterização de cartel quando ela se junta a outras congêneres para negociar preços menores com a rede credenciada.

Nos registros do CADE, constam os processos PA n ${ }^{\circ}$ 08000.020425/96-71, $P A n^{\circ}$ 08012.001098/2001-84, PA n 08012.009443/1998-15, PA n ${ }^{\circ} 08012.002153 / 2000-72$ e PA n ${ }^{\circ}$ 08012.006969/2000-75, em representações contra a UNIDAS, então CIEFAS, com a alegação de configuração de acordo entre concorrentes e exercício de posição dominante.

A fundamentação da decisão concentra-se exclusivamente na análise da similaridade das operadoras que integram a representada, com completa desconsideração do consumidor como beneficiário da modalidade autogestão, cujas negociações de preços com a rede credenciada repercutirão em seu orçamento, na definição de sua contribuição ou coparticipação nos pagamentos.

A abordagem desses julgamentos seria pertinente somente se estivesse tratando de colusão de operadoras de planos de saúde para definir preços das mensalidades, pois quando se trata de estabelecimento da mensalidade, a operadora fica por lei impedida de juntar-se a outras para definição dos preços a serem cobrados dos usuários, considerando o prejuízo ao interesse da coletividade que ela assiste. 


\section{LIVRE CONCORRÊNCIA E DEFESA DO CONSUMIDOR}

A Constituição Federal estabelece, no art. 50, inciso XXXII, a obrigação do Estado em promover a defesa do consumidor, inclui nos princípios gerais da atividade econômica, no art. 170, incisos IV e V, a livre concorrência e a defesa do consumidor e determina, no art. 173, $\S 4^{\circ}$, que a lei reprimirá o abuso do poder econômico que vise à dominação dos mercados, à eliminação da concorrência e ao aumento arbitrário dos lucros.

Denomina-se livre concorrência a liberdade de os atores definirem a sua posição no mercado, com o estabelecimento de preços e condições para produtos ou serviços sem a interferência ou influência de concorrentes, assim entendidos os que disputam entre si o fornecimento ou a aquisição de produtos ou serviços iguais ou similares de forma excludente, isto é, o sucesso de um anula ou reduz consideravelmente o do outro.

A Lei $n^{\circ} 8.078 / 90$ institui, em seu art. $4^{\circ}$, a Política Nacional das Relações de Consumo. A Lei $\mathrm{n}^{\circ} 8.137 / 90$ define, dos arts. $4^{\circ}$ ao $6^{\circ}$, crimes contra a ordem econômica e no art. $7^{\circ}$, crimes contra as relações de consumo. A Lei $n^{\circ} 12.529 / 2011$ determina, em seu art. $1^{\circ}$, a sua orientação pelos ditames constitucionais de livre concorrência e defesa dos consumidores e, no parágrafo único, que a coletividade é a titular dos bens jurídicos por ela protegidos. A Lei $n^{\circ}$ 9.961/2000 estabelece em seu art. $4^{\circ}$, inciso XXXVI, como competência da ANS articular-se com os órgãos de defesa do consumidor visando à eficácia da proteção e defesa do consumidor de serviços privados de assistência à saúde. A Súmula 469 da Segunda Seção do Superior Tribunal de Justiça (STJ) determina a aplicação do Código de Defesa do Consumidor aos contratos de plano de saúde, independentemente da modalidade.

O combate à formação de cartéis é necessário para o equilíbrio indispensável à manutenção de relações saudáveis no mercado, caracterizadas pela liberdade dos fornecedores e segurança dos consumidores.

O combate aos cartéis tem o propósito de proporcionar possibilidade de participação no mercado a todos os fornecedores para fortalecê-los individual e indistintamente e, com isso, ampliar as possibilidades de escolha para evitar que os consumidores sejam prejudicados pela eliminação ou redução da concorrência.

A finalidade do cartel é a imposição de preços e condições de produtos ou serviços com a eliminação de alternativas para o consumidor, que fica refém dessa determinação, como afirma Gheventer (2005, p. 66): 


\section{A CONFIGURAÇÃO DO CARTEL NO MERCADO DE SAÚDE SUPLEMENTAR:}

SITUAÇÃO DA AUTOGESTÃO

Cartel envolve acordos, explícitos ou tácitos, entre concorrentes que detenham parcela significativa do mercado relevante, não só para elevar preços e restringir a produção, mas também para dividir mercados ou excluir outros rivais, com o objetivo de obter lucros de monopólio. Das condutas conhecidas é a que mais claramente gera efeitos deletérios sobre o bem-estar do consumidor. O cartel priva o consumidor dos dois maiores benefícios que podem ser oferecidos por um mercado competitivo: menores preços e maior oferta de bens e serviços.

O Sistema Brasileiro de Defesa da Concorrência - SBDC, responsável por assegurar competitividade na economia por meio da prevenção e da repressão de ações que possam limitar ou prejudicar a livre concorrência, com atuação orientada pela Lei $\mathrm{n}^{\circ}$ 12.529/2011, é composto pela Secretaria de Acompanhamento Econômico - SEAE, do Ministério da Fazenda e Conselho Administrativo de Defesa Econômica - CADE, autarquia federal vinculada ao Ministério da Justiça.

O CADE, criado pela Lei 4.137/62, transformado em autarquia federal vinculada ao Ministério da Justiça pela Lei $\mathrm{n}^{\circ}$ 8.884/94, passou a ser constituído pelo Tribunal Administrativo de Defesa Econômica, Superintendência-Geral e Departamento de Estudos Econômicos, nos termos do art. $5^{\circ}$ da Lei n ${ }^{\circ}$ 12.529/2011, é responsável pela decisão final na esfera administrativa e, por ser um órgão judicante, pode aplicar penalidades aos infratores da ordem econômica e suas decisões se revestem de obrigatoriedade, com possibilidade de revogação pelo poder judiciário.

O Sistema Nacional de Defesa do Consumidor - SNDC, instituído no art. 105 da Lei $n^{\circ}$ 8.078/90 e organizado pelo Decreto $n^{\circ}$ 2.181/97, é composto pela Secretaria Nacional do Consumidor do Ministério da Justiça e os demais órgãos federais, estaduais, do Distrito Federal, municipais e as entidades civis de defesa do consumidor.

Os órgãos públicos estaduais e municipais que compõem o SNDC são as instituições de Proteção e Defesa do Consumidor - PROCON, que tutela o consumidor em face do fornecedor pela presunção de sua hipossuficiência, como órgão conciliador e, por isso, sem poder judicante, mas com poder de aplicação de multa, que orienta o reclamante a recorrer ao poder judiciário para tutela do seu pretenso direito no insucesso da conciliação. 
Dentre as entidades civis de defesa do consumidor, destaca-se o Instituto Brasileiro de Defesa do Consumidor - IDEC, fundado em 1987, sem fins lucrativos e sem vínculo com empresas, governos ou partidos políticos, com fonte de recursos financeiros para o desenvolvimento de suas atividades na anuidade paga por seus associados, na venda de assinaturas da Revista do IDEC e outras publicações, na realização de cursos e no apoio de agências de financiamento internacionais destinadas a prestar ajuda a entidades da sociedade civil.

\section{CONSIDERAÇÕES FINAIS}

A manutenção da ordem econômica e a aplicação da Política Nacional de Consumo é o objetivo de toda a legislação e de toda a estrutura instituída para acompanhar e intervir, quando necessário, para evitar ou desfazer situações que comprometam a livre concorrência e possam gerar prejuízos aos consumidores.

O cartel é uma estratégia que compromete a ordem econômica com a eliminação ou descaracterização da concorrência, sempre com prejuízo para os consumidores.

No mercado de saúde suplementar, as negociações em grupo assumem uma diferença fundamental em seu propósito e em seus efeitos: a junção de prestadores exerce pressão para um maior aumento nos preços dos serviços e o seu sucesso resulta no agravamento da situação do consumidor; a de operadoras, um aumento mais moderado nesses preços e o seu sucesso repercute beneficamente no orçamento do consumidor.

O acordo entre prestadores de serviços de saúde para definir conjuntamente seus preços configura cartel porque prejudica os consumidores em seus efeitos e em seu processo, haja vista que a pressão sobre as operadoras se dá mediante suspensão dos atendimentos.

Considerando que os preços praticados pelas operadoras de autogestão no pagamento aos prestadores credenciados são determinantes para os preços das mensalidades que serão cobradas no exercício seguinte, mediante estudos atuariais, e sensibilizam imediatamente os orçamentos dos beneficiários com coparticipação ou franquia, as operadoras podem juntar-se para negociar com prestadores e, com isso, evitar preços abusivos.

Os princípios e normas que orientam a defesa da concorrência direcionam ações e atividades para a defesa do consumidor como finalidade precípua, o que torna ilegítimo e ilegal tudo que prejudicar o consumidor, mesmo potencialmente. 


\section{A CONFIGURAÇÃO DO CARTEL NO MERCADO DE SAÚDE SUPLEMENTAR: SITUAÇÃO DA AUTOGESTÃO}

As operadoras assumem duplo papel no que tange aos preços: o de comprador, na relação com os seus prestadores credenciados e o de fornecedor, na relação com os seus beneficiários.

Uma interpretação teleológica e sistemática da legislação que regulamenta as relações de mercado, inclusive o de saúde, e de consumo leva à conclusão de que o cartel se configura no mercado de saúde suplementar na junção de prestadores de serviços para definir de forma coordenada os preços dos serviços ou materiais e no acordo orquestrado de operadoras para determinar o valor das mensalidades dos planos de saúde, considerando que tais condutas geram prejuízos aos consumidores.

Equivocado, portanto, o entendimento do CADE, expresso nos processos administrativos referidos neste trabalho, que considera infração à ordem econômica a associação de entidades de autogestão em processos negociais com prestadores de serviços de saúde, por desconsiderar a inexistência de concorrência entre as entidades filiadas, a falta de abusividade quando em posição dominante e a repercussão na vida dos consumidores.

\section{REFERÊNCIAS}

BRASIL. Constituição Federal, de 5 de outubro de 1988. Disponível em: http://www.planalto.gov.br/ccivil_03/constituicao/constituicao.htm.. Acessado em $12 / 05 / 2017$.

. Decreto ${ }^{\circ}$ 2.181, de 20 de março de 1997. Dispõe sobre a organização do Sistema Nacional de Defesa do Consumidor - SNDC. Disponível em: http://www.planalto.gov.br/ccivil_03/decreto/d2181.htm. Acessado em 12/05/2017.

. Lei no 5.764, de 16 de dezembro de 1971. Define a Política Nacional de Cooperativismo, institui o regime jurídico das sociedades cooperativas. Disponível em: http://www.planalto.gov.br/ccivil_03/leis/L5764.htm. Acessado em 12/05/2017.

. Lei ${ }^{0}$ 8.078, de 11 de setembro de 1990. Dispõe sobre a proteção do consumidor. Disponível em http://www.planalto.gov.br/ccivil_03/leis/L8078.htm. Acessado em 12/05/2017.

. Lei no 8.137, de 27 de dezembro de 1990. Define crimes contra a ordem tributária, econômica e contra as relações de consumo. Disponível em:

http://www.planalto.gov.br/ccivil_03/leis/L8137.htm. Acessado em 12/05/2017. 
Lei $\mathrm{n}^{\circ}$ 12.529, de 30 de novembro de 2011. Estrutura o Sistema Brasileiro de Defesa da Concorrência; dispõe sobre a prevenção e repressão às infrações contra a ordem econômica.

Disponível em: http://www.planalto.gov.br/ccivil_03/_ato2011-2014/2011/Lei/L12529.htm. Acessado em 12/01/2017.

. Lei $n^{\circ}$ 9.656, de 3 de junho de 1998. Dispõe sobre os planos e seguros privados de assistência à saúde. Disponível em: http://www.planalto.gov.br/ccivil_03/Leis/L9656.htm. Acessado em 12/05/2017.

. Lei $n^{\circ}$ 9961, de 28 de janeiro de 2000. Cria a Agência Nacional de Saúde Suplementar - ANS. Disponível em: http://www.planalto.gov.br/ccivil_03/leis/L9961.htm. Acessado em 12/05/2017.

. Lei $\mathrm{n}^{0} 10.185$, de 12 de fevereiro de 2001. Dispõe sobre a especialização das sociedades seguradoras em planos privados de assistência à saúde. Disponível em: http://www.planalto.gov.br/ccivil_03/leis/LEIS_2001/L10185.htm. Acessado em 12/05/2017.

CONASS. Saúde Suplementar. In: Coleção Para Entender a Gestão do SUS 2011.

Vol. 12. Brasília: CONASS, 2011.

MINISTÉRIO DA SAÚDE. CONSU. Resolução CONSU nº 08/98, de 3 de novembro de 1998. Dispõe sobre mecanismos de regulação nos Planos e Seguros Privados de Assistência à Saúde. Disponível em: http://www.ans.gov.br/index2.php?option=com_legislacao\&view=legislacao\&task=TextoLei \&format=raw\&id=307. Acessado em 12/05/2017.

ANS. Caderno de Informação da Saúde Suplementar: Beneficiários, Operadoras e Planos. Rio de Janeiro: ANS, 2011. Disponível em: http://www.ans.gov.br/images/stories/Materiais_para_pesquisa/Perfil_setor/Caderno_informa cao_saude_suplementar/2017_mes03_caderno_informacao.pdf. Acessado em 12/05/2017.

Resolução Normativa ${ }^{\circ}$ 137, de 14 de novembro de 2006. Dispõe sobre as entidades de autogestão no âmbito do sistema de saúde suplementar. Disponível em: http://www.ans.gov.br/index2.php?option=com_legislacao\&view=legislacao\&task=TextoLei \&format $=$ raw\&id=1117. Acessado em 12/05/2017.

DEPKEN, Craig A. Micro-economics demystified: a self-teaching guide. Arlington: McGraw-Hill Companies, 2006.

EVENETT, Simon; LEVENSTEIN, Margaret \& SUSLOW, Valerie Yvonne. International cartel enforcement: lessons from 1990s. Malden: Blackwell Publishers, 2001.

GHEVENTER, Alexandre. Autonomia versus controle: origens do novo mercado regulatório antitruste na América Latina e seus efeitos sobre a democracia. Belo Horizonte: UFMG, 2005.

HARRINGTON, JR., Joseph Emmett. How do cartels operate? Hannover: Foundation and Trends in microeconomics, 2006.

RYPL, Francisco Sávio. É por isso que o Brasil não vai. Porto alegre: AGE, 2006.

SAES, Maria Sylvia Macchione. A racionalidade econômica da regulamentação no mercado brasileiro de café. São Paulo: ANNABLUME, 1997. 
SOARES, Natanael Dantas. A função social do contrato de plano de saúde. Disponível em: $<$ https://s3.amazonaws.com/conpedi2/anteriores/XIX+Encontro+Nacional+-+UFCFortaleza+(09\%2C+10\%2C+11+e+12+de+junho+de+2010).pdf $>$. Acessado em 12/05/2017.

SOWELL, Thomas. Basic economics: a common sense guide to the economy. 4. Ed. New York: Basic Books, 2011.

VIANA, Ana Luiza et al. Estado e regulação da saúde. In: Regulação e Saúde - estrutura, evolução e perspectivas da assistência médica suplementar. Rio de Janeiro: ANS/Ministério da Saúde, 2002.

VILARINHO, Paulo Ferreira. O campo da saúde suplementar no Brasil à luz da teoria do poder simbólico de Pierre Bourdieu. Disponível em:

$<$ http://www.scielo.br/pdf/cebape/v2n3/v2n3a08>. Acessado em 12/05/2017. 